\title{
DIAGNOSIS AND PREDICTION OF TRANSFORMER FAULTS OF SUPPORT VECTOR MACHINE OPTIMIZED BY PARTICLE SWARM ALGORITHM
}

\author{
Yi Hu ${ }^{1}$ Niqin Jing ${ }^{2}$ \\ 1,2 Beijing Polytechnic, Beijing, 100176, China \\ Email: huyidky@sohu.com
}

\begin{abstract}
Transformer as the hub of electrical power system plays a notable role in whole power grid; hence the failure of transformer may cause huge loss and threaten the life and property security of people. The diagnosis and prediction of transformer faults is quite necessary and important. To perfect the diagnosis and prediction of transformer faults, this study developed an optimized support vector machine (SVM) based on particle swarm optimization (PSO) fault diagnosis and established diagnosis and prediction models and performed optimization selection on the parameters of the models. Finally it was verified that PSO based SVM had a high preciseness in diagnosing and predicting transformer faults, suggesting a favourable practicability.
\end{abstract}

Keywords: Particle swarm algorithm, Support vector machine, Transformer, fault diagnose

\section{Introduction}

Power transformer has functions of power transformation, transmission and distribution, which has a direct impact on the security of the whole electrical power system [1]. If the potential fault of the transformer cannot be found in time, it is easy to cause the loss of personnel property.

With the continuous improvement of the level of science and technology, more and more high and new technologies have been used in the diagnosis of transformer fault. Khan S A et al. [2] applied soft computing model and adaptive neural-fuzzy inference system in the detection of transformer faults and found that adaptive neural-fuzzy inference system was advantageous over soft computing model and had a high accuracy, which avoided the limitation of diagnosing transformer faults with dissolved gas analysis.

Malik H et al. [3] used RapidMiner software, IEC TC10 and relevant data in principle component analysis to identify early faults and classify input variables. Then they classified the early faults of electrical power transformer with extreme learning machine and compared it with fuzzy logic and artificial neural network. Dissolved gas analysis is one of the most common methods for the diagnosis of transformer faults currently [4]; however it is not perfect. Therefore this study put forward to optimize support vector machine (SVM) with particle swarm algorithm. Particle swarm optimization (PSO) is a kind of intelligent guidance based on the mutual coordination and interaction between particles in swarm, which can optimize searching [5].
The super memory of particle swarm algorithm can dynamically track the current search situation and adjust the search strategy at any time [6]. SVM is a learning method to find the optimal extremum through the optimal hyperplane and reduce the error of test set, which can guide the problems of difficult distinction in the low-dimensional space [7].

In this paper, transformer faults diagnosis and prediction models were established respectively by particle swarm algorithm optimized SVM, then the optimal selection of the parameters was made, and finally the efficacy of the models in the diagnosis and prediction of transformer faults were verified. This work offers certain reference for the diagnosis and prediction of transformer.

\section{Particle Swarm Algorithm and Support Vector Machine}

\subsection{Particle swarm optimization (PSO)}

Suppose the scale of particle swarm as $M$, the coordinate position of D-dimensional space as $x_{i}=\left(x_{i 1}, x_{i 2}, \ldots, x_{i d}, \ldots, x_{i D}\right)$, and the movement distance of particles in every iteration as the speed of particles, expressed as $v_{i}=\left(v_{i 1}, v_{i 2}, \ldots v_{i d}, \ldots v_{i D}\right)$. The adjustment formula of the flying speed in $d(d=1,2, \ldots, D)$ th dimension space was

$v_{i d}=v_{i d}+r_{1} \operatorname{rand}_{1}()\left(p_{i d}-x_{i d}\right)+r_{2} \operatorname{rand}_{2}()\left(p_{k d}-x_{i d}\right)$ 
$\left\{\begin{array}{c}v_{i d}=v_{\max }, \text { if } v_{i d}>v_{\max } \\ v_{i d}=-v_{\max }, \text { if } v_{i d}<-v_{\max }\end{array}\right.$

In equation (1), $p_{k d}$ was the historic optimal position record in particle swarm, and the difference between $p_{k d}$ and the current position was the incremental component of optimal value motion, which was processed by randomization through $\operatorname{rand}_{1}() ; p_{\text {id }}$ was the historic optimal position record of individual particles, and its difference with the current position was also used in the setting of random motion; $r_{1}$ and $r_{2}$ were acceleration constants.

In equation (2), speed $v_{i}$ refers to the highest speed. If the acceleration of the current particles made its speed component $v_{i d}$ larger than the maximum speed $v_{\max }$, then the speed of the dimension would be replaced by the maximum speed $v_{\max }$, which played a decisive role in the searching of solution space.

When $v_{\max }$ was excessively large, particles would pass the optimal solution; otherwise searching would be limited in local scope. Therefore particle could adjust its position through the following equation.

$$
x_{i d}=x_{i d}+v_{i d}
$$

Particle motion was caused by the combined action of the above three equations. The speed increment of particles was correlated to the historic optimal position and group, and the maximum speed was limited. The motion mode was effective in solving various optimization searching problems.

\subsection{Support vector machine}

SVM is used to solve problems with regard to classification. With the addition of new technology and new theory, the theory of SVM is constantly improved. Therefore, it has certain significance to the solution of the fitting and regression problems. Support vector classification machine mainly included support vector classification machine and support vector regression machine. Here C-support vector classification machine was used [8].

When the known training set was:

$$
T=\left\{\left(x_{1}, y_{1}\right),\left(x_{2}, y_{2}\right), \ldots\left(x_{g}, y_{g}\right)\right\} \in(x, y)^{g}
$$

Where $x_{i} \in X=W^{n}, y_{i} \in y=\{1,-1\}, i=1, \ldots t$

Penalty parameter $R$ and core function $K\left(x, x^{\prime}\right)$ were used to establish formulas for searching optimal solution.

$$
\begin{aligned}
& \min \frac{1}{2} \sum_{i=1}^{g} \sum_{j=1}^{g} y_{i} y_{j} \alpha_{i} \alpha_{j} K\left(x_{i}, x_{j}\right)-\sum_{j=1}^{g} a_{j} \\
& \text { s.t } \sum_{i=1}^{g} y_{i} \alpha_{i}=00 \leq \alpha_{i} \leq R, i=1,2, \ldots g
\end{aligned}
$$

Combining equations (5) and (6), the optimal solution was $\alpha^{*}=\left(\alpha_{1}^{*}, \ldots, \alpha_{1}^{*}\right)^{T}$.

Suppose a positive component of $\alpha^{*} 0<\alpha_{j}^{*}<R$, then $b^{*}=y_{j}-\sum_{i=1}^{g} y_{i} \alpha_{j}^{*} K\left(x_{i} \bullet y_{i}\right)$.

A decision function was established.

$$
f(x)=\operatorname{sgn}\left(\sum_{i=1}^{g} \alpha_{i}^{*} y_{i} K\left(x \bullet x_{i}\right)+b^{*}\right)
$$

\section{Diagnosis and Prediction of Transformer Faults Based on PSO Based SVM}

\subsection{The prediction model of transformer faults}

\section{(1) Fault model}

A fault model was developed based on multi-level binary tree support vector classification machine [9], as shown in Figure 1.

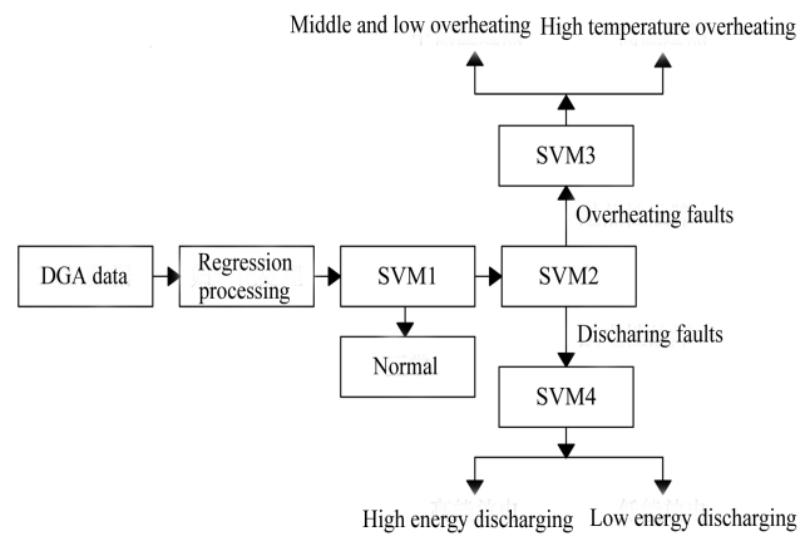

Figure 1: Fault diagnosis model

The volume data of gas volume were divided into training set and test set. The data in the training set were put into the model to training the support machine. The data in the transformer were divided into normal state and abnormal state. 
Normal state was separated with medium and low temperature overheating, high temperature overheating, high energy discharging and low energy discharging. -1 was output in normal state, and 1 was output when there was fault. Then the SVM2 was trained. The overheating and discharging data were separated; -1 was output when there was overheating fault, and 1 was output when there was discharging fault. SVM3 and SVM4 were trained separated in the same way. SVM3 divided data into middle and low temperature overheating and high temperature overheating; -1 was output when there was middle and low temperature overheating fault, and 1 was output when there was high temperature overheating. SVM4 divided data into high energy discharging and low energy discharging. -1 was output when there was high energy discharging, and 1 was output when there was low energy discharging. The four classifiers were all trained. The fault of transformer was diagnosed according to the output results of the classifiers.

\section{(2) Prediction model}

In fault prediction of power transformer, the data of dissolved gas content was time sequence. Let nonlinear time sequence $X_{N}=\left\{x_{1}, x_{2}, \ldots, x_{n}\right\}$. Suppose $x_{t}$ at time $\mathrm{t}$ was known and the data at $\mathrm{t}+1$ was predicted as $x_{t+1}$, then mapping $f: R^{m} \rightarrow R$. Let

$x_{t+1}^{*}=f\left(x_{t-m+1}, x_{t-m+2}, \ldots, x_{t}\right)$

$x_{t+1}$ is the predicted value at $\mathrm{t}+1, m$ stands for the number of embedding dimensions. The original time sequence $X_{N}$ was reconstructed. The formula of transforming time sequence to matrix form is as follows.

$X=\left[\begin{array}{c}\bar{x}_{m+1} \\ \bar{x}_{m+2} \\ \ldots \\ \bar{x}_{n}\end{array}\right]=\left[\begin{array}{cccc}x_{1} & x_{2} & \ldots & x_{m} \\ x_{2} & x_{3} & \ldots & x_{m+1} \\ \ldots & \ldots & \ldots & \ldots \\ x_{n-m} & x_{n-m+1} & \ldots & x_{n-1}\end{array}\right], Y=\left[\begin{array}{c}x_{m+1} \\ x_{m+2} \\ \ldots \\ x_{n}\end{array}\right]$

The regression function of the training for support vector machine was:

$$
f(\bar{t})=\sum_{i=1}^{n-m}\left(\alpha_{i}^{*}-\alpha_{i}\right) W\left(\overline{x_{i}}, \overline{x_{t}}\right)+b \quad t=m+1, \ldots, n
$$

The one-step prediction model was: $x_{n+1}=\sum_{i=1}^{n-m}\left(\alpha_{i}^{*}-\alpha_{i}\right) K\left(\bar{x}_{i}, \bar{x}_{n+1}\right)+b$

Where $\bar{x}_{n+1}=\left\{x_{n-m+1}, x_{n-m+2}, \ldots, x_{n}\right\}, x_{n+1}^{*}$ stands for the predicted value of $(\mathrm{N}+1)$ th data of the time sequence.

$$
x_{n+g}=\sum_{i=1}^{n-m}\left(\alpha_{i}^{*}-\alpha_{i}\right) K\left(\bar{x}_{i}, \bar{x}_{n+g}\right)+b
$$

was the

prediction model for g-th step.

$\bar{x}_{n+g}=\left\{x_{n-m+g}, x_{n-m-g+1}, \ldots, x_{n+1}, \ldots, x_{n+g-1}^{*}\right\}{ }^{*}$

was the predicted value of g-th step.

In this test, the predicted model was compared with grey model to test the reasonability of the predicted model.

\section{(3) Selection of parameters of PSO based SVM}

The specific procedures of parameter selection were: (1) Initial processing of particle swarm. Every parameter of the SVM (R and $\sigma$ ) composed a particle, and moreover the initial speed and location of every particle generated at the moment.

(2) Evaluation of adaptation. After the calculation of adaptive value, 10 -fold crossover method was used to check the evaluation of particle adaptation. The training data were randomly divided into 10 subsets which were mutually exclusive and had similar size; 9 subsets were regarded as training set, and 1 subset was regarded as validation set. After repetition for 10 times, every subset could be validated. The specific formula was:

$$
\left\{\begin{array}{c}
Q=\frac{\sum_{i=1}^{10}\left|\overline{e_{i}}\right|}{10} \times 100 \% \\
\bar{e}=\frac{f_{R}}{f_{R}+f_{e}}
\end{array}\right.
$$

Where $Q$ stands for verification classification preciseness and $f_{R}$ and $f_{e}$ refer to the number of correct and wrong classification.

(3) The individual optimal value and global optimal value were updated according to the adaptive value of procedure (2). The adaptive value of the particles in optimization was compared with the individual extremum of the historic optimal position of individuals. If the adaptive value was superior to the individual extremum of the optimal position, then the former replaced the latter. The adaptive value of particles in optimization was compared with the individual extreme of the historic optimal position of particle swarm. If the adaptive value was superior to the historic optimal position of particle swarm, then the latter was replaced by the former. 
(4) The speed and position of particles were updated. (5) The termination conditions were examined. Optimization searching reaching the maximum evolution algebra or the evaluation value smaller than the given preciseness value were set as termination conditions. It returned to procedure (2) if the termination conditions were not satisfied; otherwise optimization searching stopped.

The flow diagram is shown in Figure 2.

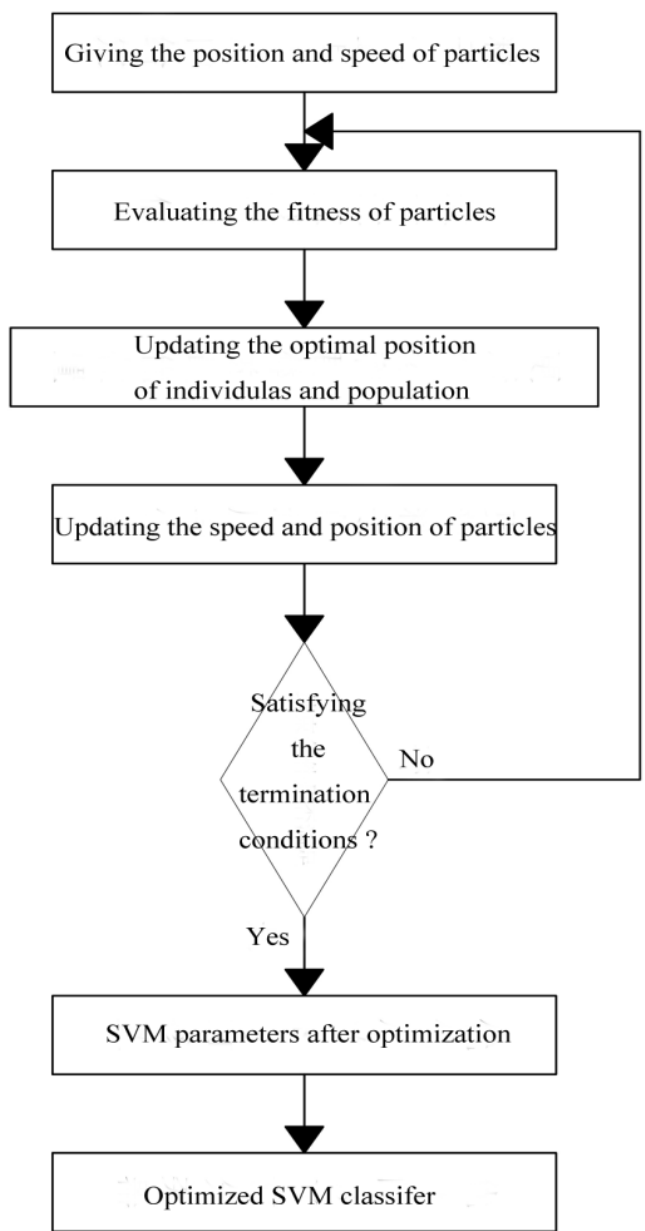

Figure 2: The flow of parameter optimization

\section{Simulation Experiment 4.1 Diagnostic results of transformer}

According to the power supply bureau and transformer fault data with definite conclusions in recent years, 450 samples were selected, and each of them had definite fault conclusion. The data were divided into training data and testing data. Among the training data, there were 64 cases of middle and low temperature overheating $\left(\mathrm{T}_{1}\right), 110$ cases of high temperature overheating $\left(\mathrm{T}_{2}\right), 73$ cases of high energy discharging $\left(D_{1}\right)$ and 109 cases of high energy discharging $\left(D_{2}\right)$; among the testing data, there were 19 cases of $\mathrm{T}_{1}, 38$ cases of $\mathrm{T}_{2}, 19$ cases of $\mathrm{D}_{1}$ and 18 cases of $\mathrm{D}_{2}$. The penalty factor and core function parameters were optimized according to SVM algorithm.
The size of the population was 10 , the inertia weight was 0.9 , and the acceleration constants were 1.4 and 1.6 respectively. Through training, the optimal value of the penalty factor was 3.692, and the parameter of the core function was 0.483 .

Table 1. Diagnostic results of faults

\begin{tabular}{|c|c|c|c|}
\hline $\begin{array}{c}\text { Types of } \\
\text { faults }\end{array}$ & $\begin{array}{c}\text { Number } \\
\text { of testing } \\
\text { samples }\end{array}$ & $\begin{array}{c}\text { Accurate } \\
\text { times of SVM }\end{array}$ & Accuracy \\
\hline $\begin{array}{c}\text { Middle and } \\
\text { low } \\
\text { temperature } \\
\text { overheating } \\
\mathrm{T}_{1}\end{array}$ & 19 & 18 & $94.74 \%$ \\
\hline $\begin{array}{c}\text { High } \\
\text { temperature } \\
\text { overheating } \\
\mathrm{T}_{2}\end{array}$ & 38 & 37 & $97.37 \%$ \\
\hline $\begin{array}{c}\text { Low energy } \\
\text { discharging } \\
\mathrm{D}_{1}\end{array}$ & 19 & 18 & $94.74 \%$ \\
\hline $\begin{array}{c}\text { High } \\
\text { temperature } \\
\text { discharging } \\
\mathrm{D}_{2}\end{array}$ & 18 & 16 & $88.89 \%$ \\
\hline Total & 94 & 89 & $94.68 \%$ \\
\hline
\end{tabular}

Table 1 demonstrates that the diagnostic accuracy of the faults except high energy discharging was higher than $90 \%$, and the diagnostic accuracy of high energy discharging was lower than 90\%, indicating that the classifier had a high practical value in engineering.

The diagnostic results of faults based on classifier are shown in Table 2.

Table 2. The detection accuracy of faults based on the

\begin{tabular}{|c|c|c|c|c|}
\hline Classifiers & $\begin{array}{l}\text { Number } \\
\text { of SVM }\end{array}$ & $\begin{array}{l}\text { Testin } \\
\text { g data }\end{array}$ & $\begin{array}{l}\text { Correct } \\
\text { data }\end{array}$ & Accuracy \\
\hline SVM1 & 5 & 94 & 94 & $100 \%$ \\
\hline SVM2 & 10 & 94 & 94 & $100 \%$ \\
\hline SVM3 & 12 & 57 & 57 & $100 \%$ \\
\hline SVM4 & 14 & 37 & 36 & $97.30 \%$ \\
\hline
\end{tabular}

Table 2 demonstrates that the fault detection rates of SVM1, SVM2 and SVM3 was all 100\%, and only the fault detection rate of SVM4 was $97.30 \%$. It indicated that PSO optimized SVM had a high accuracy.

\subsection{Prediction results of transformer faults}

The volume fractions of dissolved gases including $\mathrm{H}_{2}, \mathrm{CH}_{4}, \mathrm{C}_{2} \mathrm{H}_{6}, \mathrm{C}_{2} \mathrm{H}_{4}$ and $\mathrm{C}_{2} \mathrm{H}_{2}$ in transformer could effectively reflect the status messages of transformers. The specific parameters of the research model are shown in Table 3. 
Table 3: The parameters of the prediction model

\begin{tabular}{|l|l|l|l|l|}
\hline $\begin{array}{c}\text { Types of } \\
\text { gases }\end{array}$ & \multicolumn{1}{c|}{$\mathrm{R}$} & \multicolumn{1}{c|}{$\mathrm{x}$} & \multicolumn{1}{c|}{$\mathrm{e}$} & $\mathrm{m}$ \\
\hline $\mathrm{H}_{2}$ & 255 & 0.000978 & 1 & 6 \\
\hline $\mathrm{CH}_{4}$ & 65 & 0.00978 & 0.000978 & 7 \\
\hline $\mathrm{C}_{2} \mathrm{H}_{6}$ & 1024 & 0.00392 & 0.25 & 6 \\
\hline $\mathrm{C}_{2} \mathrm{H}_{4}$ & 65 & 0.25 & 0.000978 & 5 \\
\hline $\mathrm{C}_{2} \mathrm{H}_{2}$ & $/$ & $/$ & $/$ & $/$ \\
\hline
\end{tabular}

The detection results of SVM optimized by PSO were compared with those of grey model from 10 th October to 12 th October. The comparison is shown in Table 4

Table 4: The comparison of the detection results

\begin{tabular}{|c|c|c|c|c|}
\hline $\begin{array}{l}\text { Types } \\
\text { of } \\
\text { gases }\end{array}$ & $\begin{array}{l}\text { True } \\
\text { value }\end{array}$ & $\begin{array}{l}\text { Predicte } \\
\text { d values } \\
\text { of SVM } \\
\text { optimize } \\
\text { d by PSO } \\
\text { and grey } \\
\text { model } \\
(\mu l / l)\end{array}$ & $\begin{array}{l}\text { Relative } \\
\text { errors of } \\
\text { SVM } \\
\text { optimize } \\
d \text { by PSO } \\
\text { and grey } \\
\text { model } \\
(\%)\end{array}$ & $\begin{array}{l}\text { Mean } \\
\text { absolute } \\
\text { percentag } \\
\text { e errors } \\
\text { of SVM } \\
\text { optimized } \\
\text { by PSO } \\
\text { and grey } \\
\text { model }\end{array}$ \\
\hline \multirow{3}{*}{$\mathrm{H}_{2}$} & 124 & $\begin{array}{l}125.452 ; \\
125.998\end{array}$ & $\begin{array}{l}-1.992 ; \quad- \\
2.436\end{array}$ & \multirow{3}{*}{$\begin{array}{l}1.162 ; \\
1.879\end{array}$} \\
\hline & 125 & $\begin{array}{l}124.252 \\
127.002\end{array}$ & $\begin{array}{l}0.599 ; \quad- \\
1.602\end{array}$ & \\
\hline & 126 & $\begin{array}{l}124.872 ; \\
128.013\end{array}$ & $\begin{array}{l}0.895 ; \quad- \\
1.598\end{array}$ & \\
\hline \multirow{3}{*}{$\mathrm{CH}_{4}$} & 34.8 & $\begin{array}{l}35.224 ; \\
34.893\end{array}$ & $\begin{array}{l}-1.511 ; \quad- \\
0.554\end{array}$ & \multirow{3}{*}{$\begin{array}{l}0.824 ; \\
1.543\end{array}$} \\
\hline & 35.6 & $\begin{array}{l}35.346 ; \\
34.814\end{array}$ & $\begin{array}{l}0.432 ; \\
1.931\end{array}$ & \\
\hline & 35.6 & $\begin{array}{l}35.305 ; \\
34.737\end{array}$ & $\begin{array}{l}0.547 ; \\
2.147 \\
\end{array}$ & \\
\hline \multirow{3}{*}{$\mathrm{C}_{2} \mathrm{H}_{6}$} & 134 & $\begin{array}{l}134.301 ; \\
133.974\end{array}$ & $\begin{array}{l}-0.978 ; \quad- \\
0.731\end{array}$ & \multirow{3}{*}{$\begin{array}{l}1.496 ; \\
2.921\end{array}$} \\
\hline & 138 & $\begin{array}{l}135.086 ; \\
133.203\end{array}$ & $\begin{array}{l}1.395 ; \\
2.771\end{array}$ & \\
\hline & 141 & $\begin{array}{l}\text { 141.948; } \\
131.635\end{array}$ & $\begin{array}{l}-2.118 ; \\
5.260\end{array}$ & \\
\hline \multirow{3}{*}{$\mathrm{C}_{2} \mathrm{H}_{4}$} & 46.4 & $\begin{array}{l}45.801 ; \\
46.773\end{array}$ & $\begin{array}{l}1.502 ; \\
0.233\end{array}$ & \multirow{3}{*}{$\begin{array}{l}0.751 ; \\
1.396\end{array}$} \\
\hline & 46.1 & $\begin{array}{l}45.894 ; \\
46.773\end{array}$ & $\begin{array}{l}0.664 ; \quad- \\
1.242\end{array}$ & \\
\hline & 45.6 & $\begin{array}{l}45.658 ; \\
46.938\end{array}$ & $\begin{array}{ll}0.090 ; \quad- \\
2.699\end{array}$ & \\
\hline $\mathrm{C}_{2} \mathrm{H}_{2}$ & 1 & / & / & / \\
\hline
\end{tabular}

Table 5 suggests that the relative errors of SVM optimized by PSO were larger than those of grey model in the prediction of $\mathrm{CH}_{4}$ and $\mathrm{C}_{2} \mathrm{H}_{4}$ on 10 th October and smaller than those of grey model on other dates. Om addition, the average absolutes values of the prediction of volume content of the four gases with the two models were both smaller than $1.5 \%$, and the value of SVM optimized by PSO was smaller than that of grey model. Therefore the preciseness of SVM optimized by PSO was higher and had favorable practicability.

\section{Discussion and Conclusion}

With the rapid development of electrical power system, the pivotal role of power transformer has become more and more important.

The common abnormalities of transformer mainly include normal voice, oily flavor, oil temperature and abnormal surface. The faults included electrical faults and heat faults [10]. Electrical faults were mainly divided into local discharging, electric spark discharge and high energy discharging [11]. The characteristic gases produced by local discharging included $\mathrm{H}_{2}$ and $\mathrm{CH}_{4}$, gases produced by high energy discharging included $\mathrm{H}_{2}$, $\mathrm{C}_{2} \mathrm{H}_{2}, \mathrm{CH}_{4}$ and $\mathrm{C}_{2} \mathrm{H}_{4}$, and the characteristic gases produced by electric spark discharge included $\mathrm{H}_{2}$, $\mathrm{C}_{2} \mathrm{H}_{2}$ and $\mathrm{C}_{2} \mathrm{H}_{4}$. Heat faults refers to an excessively high temperature (higher than $700{ }^{\circ} \mathrm{C}$ ) produced by power transformer, and $\mathrm{CH}_{4}$ and $\mathrm{C}_{2} \mathrm{H}_{4}$ can be produced. With the improvement of temperature, the percentage of $\mathrm{C}_{2} \mathrm{H}_{4}$ increases gradually $[12,13]$. After summary of the aforementioned faults, the main categories of faults can be divided into middle and low temperature overheating, high temperature overheating, low energy discharging and high energy discharging [14]. This study explored the diagnosis and prediction of transformer faults using SVM optimized by PSO. In the study of predicting the categories of faults, five relevant gases were selected; the preciseness of prediction of SVM optimized by PSO and grey model was compared. Finally it was concluded that SVM optimized by PSO had a high accuracy in diagnosing and predicting transformers and also a favorable practicability; hence the method has certain feasibility.

\section{Acknowledgement}

This study was supported by the General Project of Science and Technology Plan of Beijing Education Committee (16ZX004).

\section{References}

[1] Pudlo G, Tenbohlen S, Linders M, and Krost G., "Integration of power transformer monitoring and overload calculation into the power system control surface" Transmission and Distribution Conference and Exhibition 2002: Asia Pacific. IEEE/PES. IEEE, 2002(1): 470-474

[2] Khan S. A., Equbal M. D. and Islam T., "A comprehensive comparative study of DGA based transformer fault diagnosis using fuzzy logic and ANFIS models" IEEE Transactions on Dielectrics \& Electrical Insulation, 2015, 22(1):590-596.

[3] Malik H. and Mishra S., "Extreme learning machine based fault diagnosis of power transformer using IEC TC10 and its related data" India Conference. IEEE, 2016:1-5. 
[4] Su Q., Mi C., Lai L. L. and Austin A., "A fuzzy dissolved gas analysis method for the diagnosis of multiple incipient faults in a transformer" IEEE Transactions on Power Systems Pwrs, 2000, 15(2):593-598.

[5] Zhang J. L., Dai D. W., "A Particle Swarm Optimization Algorithm Based on the Pattern Search Method" Advanced Materials Research, 2012, 532-533:1664-1669.

[6] Ma W, Sun Z. X., Li J. L., Song M. and Lang X. F., “An improved artificial bee colony algorithm based on the strategy of global reconnaissance" Soft Computing, 2015:1-33.

[7] Flouri K., Beferull-Lozano B. and Tsakalides P., "Training a SVM-based classifier in distributed sensor networks" Signal Processing Conference, 2006, European. IEEE, 2015:1-5.

[8] Schuldt C., Laptev I. and Caputo B., "Recognizing Human Actions: A Local SVM Approach" International Conference on Pattern Recognition. IEEE, 2004:32-36 Vol.3.

[9] Sidaoui B. and Sadouni K., "Binary tree multi-class SVM based on OVA approach and variable neighbourhood search algorithm" International Journal of Computer Applications in Technology, 2017, 55(3):183.
[10] Du L., Yuan L. and Wang Y., "Power transformer multi-parameter fault fusion diagnosis method" International Conference on High Voltage Engineering and Application. IEEE, 2010:608613.

[11] Harjo S. and Sutikno H., "Effects of temperature on the breakdown voltage and partial discharge patterns of biodegradable oil" International Conference on Electrical Engineering and Informatics. IEEE, 2011:1-6.

[12] Wang Q., Hao J., Huang H. X., Zhou M. and Zhou Q., "Adsorption energy and charge transfer of tin oxide to characteristic gases dissolved in transformer oil" IEEE International Conference on High Voltage Engineering and Application. IEEE, 2016:1-3.

[13] Li C., Qing G., Li P. and Yin T., "Operational Risk Assessment of Distribution Network Equipment Based on Rough Set and D-S Evidence Theory" Journal of Applied Mathematics, 2013, (201312-23), 2013, 2013(1):1-7.

[14] Ge Y. T. and Tassou S. A., "Control optimisation of $\mathrm{CO} 2$, cycles for medium temperature retail food refrigeration systems" International Journal of Refrigeration, 2009, 32(6):13761388.

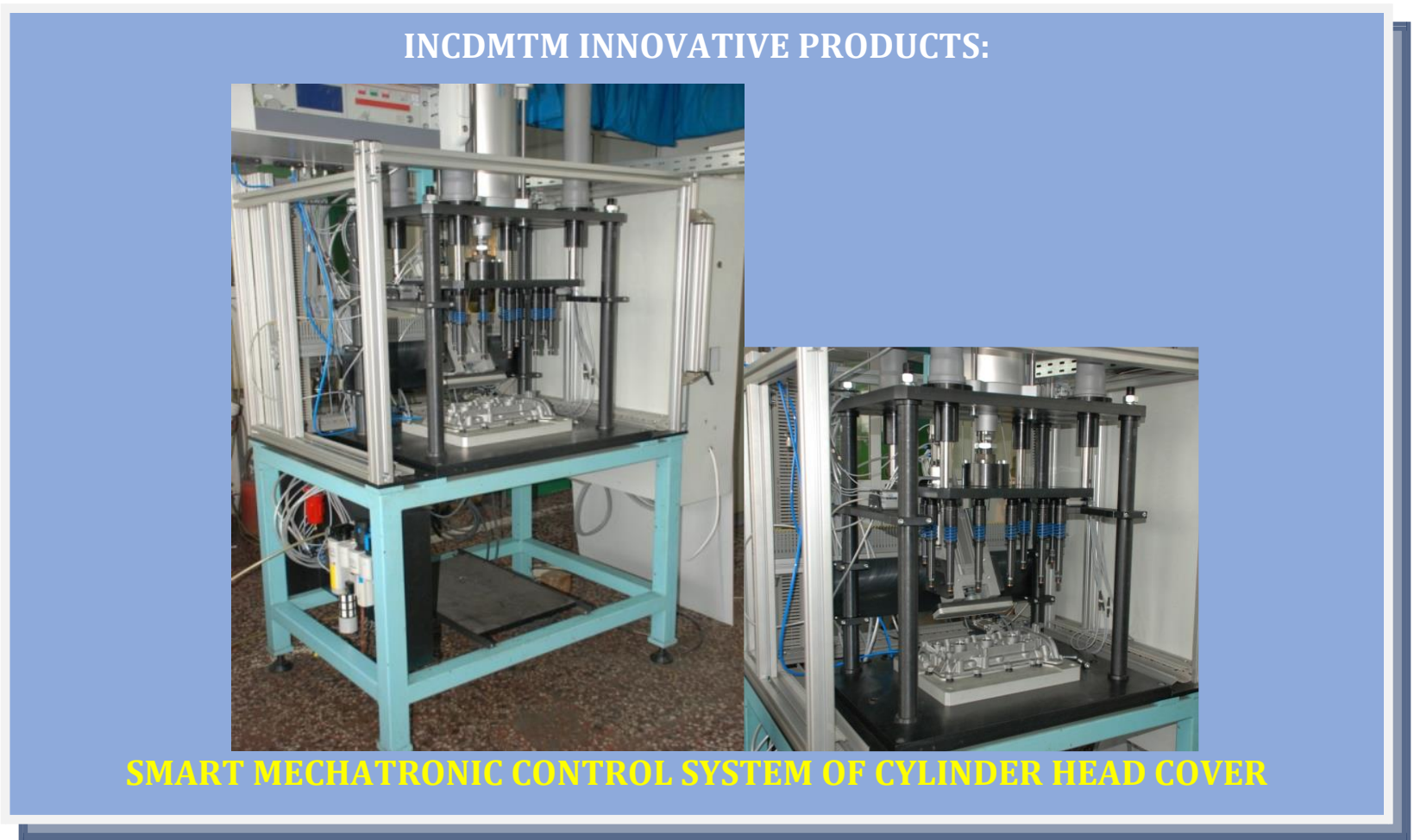

